\title{
ANALISIS BREAK EVEN SEBAGAI ALAT PERENCANA LABA: KASUS PADA TOKO PUTRA PASTI MANDIRI CIKAMPEK KARAWANG
}

\section{Santi Pertiwi Hari Sandi}

santi.pertiwi@ubpkarawang.ac.id

\begin{abstract}
Abstrak
Tujuan sebuah perusahaan adalah untuk memperoleh keuntungan atau laba yang dapat di pergunakan untuk kelangsungan hidup. Mendapatkan keuntungan atau laba dan besar kecilnya laba sering menjadi ukuran kesuksesan suatu manajemen. Hal tersebut didukung oleh kemampuan manajemen di dalam melihat kemungkinan dan kesempatan dimasa yang akan datang.

Cikampek terdapat perkampungan yang penduduknya merupakan pengrajin boneka, Kampung boneka tersebut terletak di Cikampek utara tepatnya di Desa Mekar sari dan lebih dikenal sebagai Kampung baru (Kamba). Lokasi kampung boneka ini tidak jauh dari Stasiun Cikampek, Di kampung tersebut terdapat kurang lebih 50 rumah yang memproduksi boneka dan setiap rumah rata-rata terdapat 5 hingga 10 pekerja yang membuat boneka. (Kompasiana, 21/11/2011). Usaha ini dimulai dari taun 1980. Berkembang pesatnya industri boneka mendukung berkembangnya usaha dalam pemenuhan bahan baku pembuatan usaha tersebut, salah satu usaha yang menjalani pemenuhan bahan baku pembuatan boneka, topi dan lain-lain adalah Usaha dangang Putra Pasti Mandiri (PPM). Usaha ini merupakan usaha keluarga yang di dirikan pada tahun 1998, berikut merupakan laba yang diperoleh selama tiga tahun terakhir.

Volume penjualan di mana penghasilannya (revenue) tepat sama besarnya dengan biaya totalnya, sehingga perusahaan tidak mendapatkan keuntungan atau menderita kerugian dinamakan Break Even Point (Bambang Riyanto, 2010 : 360). Rumusan untuk menghitung BEP $=$ titik impas

Penelitian ini bertujuan untuk mengetahui gambaran keseluruhan Break Even toko PPM melalui biaya tetap, biaya variable, dan volume penjulan, sehingga bisa menetukan penjulan minimum agar tidak mengalami kerugian dan menentukan perencanaan laba yang akan di capai oleh pemilik Toko. Metode pada penelitian ini menggunakan pendekatan expost facto karena
\end{abstract}


variabel yang diteliti tidak dikenai suatu tindakan, perlakuan atau manipulasi, melainkan hanya meneliti dan mengungkapkan faktor-faktor yang diteliti berdasarkan keadaan yang sudah ada. Kata Kunci : Break Even, total fixes cost, total variable cost, sales, perencana laba

\section{Latar Belakang}

Perencanaan laba memerlukan alat bantu berupa analisis biaya-volume-laba. Salah satu teknik analisis biaya-volume-laba adalah analisis break even. Impas sendiri di artikan keadaan suatu usaha yang tidak memperoleh laba dan tidak menderita rugi. Dengan kata lain suatu usaha di katakan impas jika jumlah pendapatan sama dengan jumlah biaya. Dengan demikian analisis break even adalah suatu alat yang di gunakan untuk mempelajari hubungan antara biaya tetap, biaya variabel, keuntungan dan volume penjualan (Bambang Riyanto, 2010;359). Dengan melakukan analisis break even, manajemen akan memperoleh informasi tingkat penjualan minimal yang harus dicapai, agar tidak mengalami kerugian. Dari analisis tersebut, juga dapat diketahui sampai seberapa jauh volume penjualan yang direncanakan boleh turun, agar perusahaan tidak mengalami kerugian. Analisis break even menyajikan informasi hubungan biaya, volume dan laba kepada manajemen. Sehingga memudahkan dalam menganalisis faktor yang mempengaruhi pencapaian laba perusahaan dimasa yang akan datang.

Cikampek terdapat perkampungan yang penduduknya merupakan pengrajin boneka, Kampung boneka tersebut terletak di Cikampek utara tepatnya di Desa Mekar sari dan lebih dikenal sebagai Kampung baru (Kamba). Lokasi kampung boneka ini tidak jauh dari Stasiun Cikampek, Di kampung tersebut terdapat kurang lebih 50 rumah yang memproduksi boneka dan setiap rumah rata-rata terdapat 5 hingga 10 pekerja yang membuat boneka. (Kompasiana,

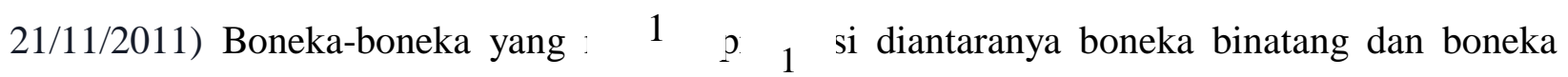
tokoh kartun. Selain boneka, para pengrajin ını juga memproduksi tas karakter tokoh kartun, bantal, topi anak-anak dan tempat pensil. Menurut keterangan seorang pengrajin industri ini mulai ada sejak tahun 1980. Wilayah pemasaran boneka-boneka ini mencakup Daerah Jawa barat, Jawa tengah, Jawa timur, Kalimantan, Sumatera dan daerah-daerah lain di luar pulau Jawa. Selain dipasarkan secara langsung juga terdapat distributor yang menyalurkannya.

Berkembang pesatnya industri boneka mendukung berkembangnya usaha dalam pemenuhan bahan baku pembuatan usaha tersebut, salah satu usaha yang menjalani pemenuhan bahan baku pembuatan boneka, topi dan lain-lain adalah Usaha dagang Putra Pasti Mandiri (PPM). Usaha ini 
merupakan usaha keluarga yang di dirikan pada tahun 1998, berikut merupakan data penjualan tahun 2016.

Tabel 1.1 Penjualan tahun 2016

\begin{tabular}{|l|lr|}
\hline \multicolumn{1}{|c|}{ Bulan } & \multicolumn{2}{c|}{ Jumlah } \\
\hline Januari & Rp & $116,874,500$ \\
\hline Februari & Rp & $112,697,800$ \\
\hline Maret & Rp & $93,905,500$ \\
\hline April & Rp & $105,330,500$ \\
\hline Mei & Rp & $80,000,000$ \\
\hline Juni & Rp & $81,420,500$ \\
\hline Juli & $\mathrm{Rp}$ & $61,091,500$ \\
\hline Agustus & $\mathrm{Rp}$ & $119,055,100$ \\
\hline September & $\mathrm{Rp}$ & $76,189,500$ \\
\hline Oktober & $\mathrm{Rp}$ & $75,050,000$ \\
\hline Nopember & $\mathrm{Rp}$ & $101,818,000$ \\
\hline Desember & $\mathrm{Rp}$ & $197,807,100$ \\
\hline
\end{tabular}

Sumber : Toko Putra Pasti Mandiri (2016)

Berikut merupakan laba yang diperoleh selama 4 (empat) tahun terakhir.

Tabel 1.2

Laba Toko Putra Pasti Mandiri

Tahun 2013-2016

\begin{tabular}{|c|c|}
\hline Tahun & Total Laba \\
\hline 2013 & Rp. 70.079 .500 \\
\hline 2014 & Rp. 15.635 .500 \\
\hline 2015 & Rp. 38.300 .500 \\
\hline 2016 & Rp. 67.265.775 \\
\hline
\end{tabular}

Sumber: Toko Putra Pasti Mandiri (2016) 


\subsection{Identifikasi Masalah}

1. Pencatatan keuangan masih dilakukan secara sederhana

2. Belum adanya laporan keuangan

3. Perusahaan belum efektif dalam merencanakan laba melalui break even

4. Pemisahan biaya variable dan biaya tetap belum secara tepat

5. Tingkat break even untuk merencanakan laba belum dihitung

6. Perusahaan belum dapat menghitung dengan tepat jumlah penjualan yang harus dicapai perusahaan untuk memenuhi break even

\subsection{Perumusan Masalah}

Berdasarkan latar belakang masalah di atas, maka dapat dirumuskan permasalahan adalah sebagai berikut :

1. Berapa penjualan yang sudah direalisasikan agar Toko Putra Pasti Mandiri tidak mengalami kerugian tahun 2016 ?

2. Berapa jumlah penjualan minimal Toko Putra Pasti Mandiri agar laba bisa tercapai pada tahun 2016 ?

3. Bagaimana akibat dari perubahan elemen penentu break even point terhadap perencanaan laba yang direncanakan Toko Putra Pasti Mandiri tahun 2016?

\section{Landasan Teori}

Manajemen Keuangan secara umum (dalam bahasa inggris disebut finance) mencakup tiga area yang saling berkaitan, yaitu perbankan dan pasar modal (money and capital markets atau macro finance), investasi (investments), dan manajemen keuangan (financial management atau busisness finance). Manajemen keuangan adalah area yang berkaitan secara langsung dengan pengelolaan dana (financing and investing activities) dalam suatu perusahaan. Menurut Hansen dan Mowen (2006:274) Titik impas (break even point) adalah titik dimana total pendapatan sama dengan total biaya, titik di mana laba sama dengan nol. Analisis break even menurut Bambang Riyanto (2010:359) adalah suatu teknik analisis untuk mempelajari hubungan antara biaya tetap, biaya variabel, keuntungan dan volume kegiatan. 
Analisa break even point membutuhkan asumsi tertentu sebagai dasarnya. Asumsi-asumsi yang dimaksud adalah sebagai berikut (Subardi, 2008: 243)

1. Semua biaya dapat diklasifikasikan dan diukur secara realistis sebagai biaya tetap dan biaya variabel

2. Harga jual per unit tidak berubah baik untuk jumlah penjualan sedikit maupun banyak atau dengan kata lain analisis break event point tidak mengakui potongan harga karena jumlah pembelian.

3. Hanya terdapat satu jenis produk, apabila perusahaan memproduksi lebih dari satu jenis produk, maka harus dianggap satu jenis produkdengan proporsi yang tetap dan konstan.

4. Kebijakan manajemen tentang operasi perusahaan tidak berubah secara material dalam jangka waktu pendek.

5. Tingkat harga pada umumnya akan tetap stabil dalam jangka waktu pendek.

6. Persediaan tetap konstan atau tidak ada persediaan.

7. Efisiensi dan produktifitas per karyawan tidak berubah.

\section{Operasionalisasi Variabel}

TABEL 3.1

OPERASIONALISASI VARIABEL

\begin{tabular}{|c|c|c|}
\hline VARIABEL & DIMENSI & INDIKATOR \\
\hline \multirow{2}{*}{ Break Even } & $B E P(R p)$ & $\begin{array}{l}\text { 1. Total Fixed Cost } \\
\text { 2. Total Variable Cost } \\
\text { 3. Total Sales }\end{array}$ \\
\hline & $B E P(Q)$ & $\begin{array}{l}\text { 1. Total Fixed Cost } \\
\text { 2. Variable Cost per unit } \\
\text { 3. Price per unit }\end{array}$ \\
\hline Perencanaan Laba & Laba & $\begin{array}{l}\text { Tujuan dan target laba yang } \\
\text { realistis }\end{array}$ \\
\hline
\end{tabular}


Sumber: Bambang Riyanto (2013:364)

Adolph Matz (1992:4)

\section{Metode Penelitian}

Secara umum metode penelitian diartikan sebagai cara ilmiah untuk mendapatkan data dengan tujuan dan kegunaan tertentu (Sugiyono, 2010:2 Metode pada penelitian ini menggunakan pendekatan expost facto karena variabel yang diteliti tidak dikenai suatu tindakan, perlakuan atau manipulasi, melainkan hanya meneliti dan mengungkapkan faktor-faktor yang diteliti berdasarkan keadaan yang sudah ada.

Instrumen penelitian difokuskan pada Toko Putra Pasti Mandiri yaitu:

1. Perhitungan Break Even

2. Perencanaa Laba

\section{Metode Pengumpulan Data}

\section{Dokumentasi}

Dokumentasi yaitu teknik pengumpulan data yang dilakukan dengan jalan mengadakan pencatatan, pengumpulan bahan-bahan tertulis, yang mempunyai keterkaitan dengan permasalahan yang tengah peneliti amati. Data yang diperoleh dari Toko adalah :
a. Data realisasi penjualan tahun 2016
b. Data realisasi biaya produksi tahun 2016
c. Data realisasi harga jual tahun 2016
d. Data anggaran biaya produksi tahun 2016
e. Data anggaran harga jual tahun 2016
a. Data anggaran penjualan tahun 2016

\section{Hasil dan Pembahsan}

1. Break even point yang dialami Toko Putra Pasti Mandiri tahun 2016, Break even point yang dimana perusahaan tidak mendapatkan keuntungan dan juga tidak mengalami kerugian. Break even point yang dialami Toko Putra Pasti Mandiri pada tahun 2016 adalah sebagai berikut: 


$$
\begin{aligned}
& \text { BEP total }=\frac{187.330 .000}{28.07 \%}=\text { Rp. } 667.367 .296 \\
& \text { BEP A }=\frac{131.131 .000}{34.54 \%}=\text { Rp. } 379.649 .681,5 \\
& \text { BEP B }=\frac{56.199 .000}{6.81 \%}=\text { Rp. } 825.242 .290,7
\end{aligned}
$$

2. Jumlah penjualan minimal yang harus dicapai untuk mencapai laba yang direncanakan Toko Putra Pasti Mandiri tahun 2016, Menentukan target keuntungan atau profit margin bagi perusahaan salah satu perencanaan yang dilakukan manajemen perusahaan.

Perusahaan menetapkan profit margin atau target keuntungan sebesar 25\%. Dengan target keuntungan tersebut dapat dihitung besarnya penjualan minimal sebagai berikut:

$$
\begin{array}{ll}
\text { Penjualan minimal } & =\mathrm{x} \\
& =\frac{\text { Rp. } 187.330 .000+25 \%}{28.07 \%} \\
& = \\
28.07 \% \mathrm{x} & =\text { Rp. } 187.330 .000+25 \% \\
28.07 \%-25 \% \mathrm{x} & =\text { Rp. } 187.330 .000 \\
3.07 \% \mathrm{x} & =\text { Rp. } 187.330 .000 \\
\mathrm{X} & =\text { Rp. } 6.101 .954 .397
\end{array}
$$

Tahun 2016 untuk memperleh keuntungan 25\% dari penjualan maka perusahaan harus dapat menjual dan memproduksi produk sebesar Rp.6.101.954.379.

3. Besar margin of safety atau batas keamanan agar jumlah penjualan Toko Putra Pasti Mandiri boleh berkurang dari rencana semula sehingga perusahaan tidak menderita 
rugi, dari data BEP dan contribution margin anggaran penjualan tahun 2016 adalah sebagai berikut:

Margin of Safety (MOS) total tahun 2016 dapat dihitung sebagai berikut:

$$
\operatorname{MOS}=\frac{\text { Anggaran penjualan - BEP }}{\text { Anggaran penjualan }} \times 100 \%
$$

MOS rupiah $=$ MOS $x$ anggaran penjualan

$$
\operatorname{MOS}=\frac{1.111 .146 .400-667.367 .296}{1.111 .146 .400} \times 100 \%=40 \%
$$

dalam rupiah $=40 \%$ x 1.111.146.400 $=$ Rp. 444.458 .560

Margin of Safety (MOS) masing-masing produk tahun 2016 dapat dihitung sebagai berikut:

$$
\operatorname{MOS} \mathrm{A}=\frac{854.686 .000-379.649 .681,5}{854.686 .000} \times 100 \%=55.5 \%
$$

dalam rupiah $=55.5 \% \times 854.686 .000=\mathrm{Rp} .474 .350 .730,00$

$$
\begin{aligned}
& \operatorname{MOS} \mathrm{B}=\frac{256.460 .400-825.242 .290,7}{\mathrm{x}} \times 100 \%=-321.68 \% \\
& \text { dalam rupiah }=-321258 \% 146.02460 .400 .400=- \text { Rp. 824.981.814.7 }
\end{aligned}
$$

Margin of Safety menunjukan jarak antara penjualan yang direncanakan dengan penjualan pada break even. Dengan demikian margin of safety juga menggambarkan batas jarak, dimana kalau berkurangnya penjualan melampaui batas jarak tersebut perusahaan akan menderita kerugian. Margin of safety tahun 2016 sebesar 40\% menunjukan bahwa jumlah penjualan yang 
nyata berkurang atau menyimpang lebih besar dari $40 \%$ (dari penjualan yang direncanakan) perusahaan akan menderita rugi.

Margin of safety masing-masing produk tahun 2016 pada busa strop A sebesar $55.5 \%$ sedangkan pada busa strop B sebesar -321.68\%. Hasil ini menunjukan penjualan busa strop B lebih rawan mengalami kerugian karena memiliki MOS lebih kecil dari busa strop A. Semakin kecil MOS berarti semakin cepat perusahaan menderita kerugian, dalam hal ini terdapat penurunan jumlah penjualan yang nyata.

4. Bagaimana akibat dari perubahan elemen penentu break even terhadap perencanaan laba perusahaan?

Jawab: Elemen yang menentukan break even poin yaitu: harga jual, biaya tetap, serta perubahan komposisi penjualan, apabila salah satu faktor berubah (tanpa mempengaruhi faktor lain) maka akan mempengaruhi jumlah BEP.

a. Apabila komposisi penjualan produk berubah dari semula (secara individu) maka komposisi contribution margin akan berubah. Hal ini akan menyebabkan BEP berubah total, karena hasil penjualan dari komposisi yang baru berbeda dengan komposisi semula.

b. Apabila anggaran biaya tetap naik dan anggaran lain tidak berubah maka BEP naik. Hal tersebut menyebabkan laba perusahaan turun. Sedangkan apabila anggaran biaya tetap turun maka BEP turun dan laba naik. Besarnya contribution margin (CM) tidak terpengaruh oleh biaya tetap namun perannya cukup besar dalam perolehan laba perusahaan seperti tertera pada tabel bahwa produk yang memiliki contribution margin tinggi, penurunan laba akibat perubahan biaya tetap relatif lebih kecil dibanding produk yang mempunyai contribution margin rendah. Manajemen dapat mengantisipasi penurunan laba operasi bila terjadi perubahan anggaran biaya tetap dengan meningkatkan penjualan produk yang memiliki contribution margin tinggi agar laba total yang diinginkan dapat tercapai. 
c. Apabila kenaikan kenaikan harga jual tahun 2016 sebesar 7,5\% (tidak berpengaruh pada biaya dan anggaran lainnya) menyebabkan BEP turun sebesar Rp.513.936.899.9, dan laba naik sebesar Rp. 271.128.250. Sedangkan penurunan harga jual menyebabkan BEP naik Rp. 841.932.584.3 dan penurunan laba sebesar Rp. 841.932.584.3

\section{Daftar Pustaka}

Buku: Abdul Halim dan Bambang Supomo. (2005). Akuntansi Manajemen. Edisi Pertama. Yogyakarta: BPFE.

Baker, Bill (2007). Destination Branding for Small Cities the Essentials for Successful Place Branding. Oregon USA:Creative Leap Books.

Bambang Riyanto. (2010). Dasar-dasar Pembelanjaan Perusahaan. Yogyakarta: BPFE.

Handoyo Wibisono. (1997). Manajemen Modal Kerja. Yogyakarta: Andi Offset

Henry Simamora. (1999). Akuntansi Manajemen. Yogyakarta: Salemba Empat.

Hansen, Don. R dan Maryanne M. Mowen. (2006). Akuntansi Biaya. Edisi Ketujuh. Jilid 2. Jakarta: Salemba Empat.

- (2000) Akuntansi Manajemen, Edisi Kedua, terjemahan : A. Hermawan, Penerbit Erlangga, Jakarta

Matz, Adolph dkk. (1992). Akuntansi Biaya Perencanaan dan Pengendalian. Edisi Kesembilan Jilid 2. Jakarta: Erlangga. 
Mulyadi. (2007). Akuntansi Biaya. Edisi Kelima. Yogyakarta: UPP STIM YKPN.

Soehardi. 2002. Analisa Break Even Point. Yogyakarta: BPFE Carter, William. K dan Milton F. Usry. (2006). Akuntansi Biaya. Edisi Ketigabelas. Buku Satu. Jakarta: Salemba Empat.

Subardi, agus. 2008. Manajemen Keuangan, Jilid 2. Yogyakarta: AMP YKPN.

Sugiyono. (2010). Metode Penelitian Bisnis. Bandung:Alfabeta.

\section{Jurnal:}

Christina, Rinda. 2013. Analisis Hubungan Break Even Point dengan Perencanaan Laba Jangka Pendek pada CV Adi Putra Utama Palembang. STIE MDP

Cintya, Sacharina. 2014. Analisis Break Even Point Sebagai Alat Perencana Laba Perusahaan pada Industri Pengolahan Tebu di Pabrik Gula Tasikmadu Kabupaten Karanganyar Tahun 20122013 (Studi Kasus Pada PG. Tasik Madu Karanganyar). Universitas Muhammadiyah Surakarta.

Hutani, Sulina Surika, et al. (2015). Analisis Break Even Point Usaha Kerupuk SingkongUUD Kelompok Tani Kulim Unggul Kelurahan Kulim Kota Pekanbaru. Universitas RiauVolume 2, Number 2 (2015).

\section{Penelitian :}

Agustina Pradita Maehaeni. 2011. Analisis Break Even Point Sebagai Alat Perencanaan Laba pada Industri Kecil Tegel di Kecamatan Pedurungan Periode 2004-2008 (Studi Kasus usaha manufaktur). Universitas Dipenegoro

Anisa Solihat. 2011. Pengaruh Penetapan Break Even Point. Terhadap Laba pada PT. Semen Gresik (Persero) Tbk. Universitas Mercubuana Jakarta. 
Aulia Puspita KD. 2012. Analisis Brak Even terhadap Perencanaan Laba PR. Kreatifa Hasta Mandiri Yogyakarta. Universitas Negeri Yogyakarta

Dahlia HB. 2011. Analisis Biaya-Volume-Laba sebagai Alat Bantu dalam Perencanaan Laba PT Pabrik Gula Takalar. Universitas Hasanudin Makasar.

Dewi Rakhmawati. 2008. Analisis Break Even Point (BEP) pada Usaha Pengelolaan Pucuk Daun The (Kasus di Pabrik Teh Sumber Daun Kabupaten Cianjur). Universitas Sebelas Maret Surakarta.

Wahyudi Prasetyo. 2010. Analisis Break Even Point (BEP) pada Industri Pengolahan Tebu di Pabrik Gula (PG) Mojo Kabupaten Sragen. Universitas Sebelas Maret Surakarta.

Yogi Dwi Lestari. 2012. Analsis Break Even Point (BEP) Sebagai Dasar Perencanaan Laba dan Penjualan (Studi Kasus pada Usaha Kerupuk Rambak UF Wahyu Abadi Tulungagung) . Universitas Islam Negeri Maulana Malik Ibrahim Malang.

\section{Internet:}

http://www.karawangkab.go.id

https://mumtazsyamila.wordpress.com/2016/03/02/menyiapkan-kenyamanan-kota-cikampek/ http://cikampekc.blogspot.com/

http://www.kompasiana.com/lutfilaila/negeri-boneka-di-cikampek 21 November 2011 05:04:51

Diperbarui: 25 Juni 2015 23:24:13, diakses 7 Desember 2016 11.05 WIB

http://peluangusaha.kontan.co.id/news/sentra-boneka-cikampek-surga-berburu-aneka-boneka-

lucu-1. Senin, 07 November 2011 / 16:22 WIB diakses 7 Desember 2016 11.07 WIB

http://koleksiboneka.com/grosir-boneka-cikampek/ pusat grosir boneka cikampek, hargamurahdanberkualitas 